\title{
Increased papilla between implant and tooth with TEH use of hyaluronic acid injection: A case report
}

\author{
Alexandre Domingues Teixeira Neto ${ }^{1, *}$, Carmen Lucia Mueller Storrer², Felipe Rychuv Santos ${ }^{3}$, \\ Tatiana Miranda Deliberador ${ }^{4}$ \\ Professor, Dept. of Odontology Graduate, Positivo University, Brazil \\ *Corresponding Author: \\ Email: tdeliberador@gmail.com
}

\begin{abstract}
The lack of dental papilla in the anterior maxila leaves unsightly smile and the dissatisfied patient. Several surgical techniques can be performed to gain interdental papilla, but few of them are predictable. This case report shows a multidisciplinary treatment alternative to increase disabled papillae in single-tooth implant in an aesthetic region with the use of injectable hyaluronic acid. Monitoring and evaluation of results was made by clinical and photographic monitoring of the progressive increase of the papilla in millimeter measurements through computer software. After 8 applications in 5 months, prosthetic emergence profile of adjacent tooth modification, papillary inflammatory process induction, we can observe 1,0 mm papilla gain. It can be concluded that the use of injectable hyaluronic acid in association with gingival prosthetic conditioning led to increased gingival papilla between tooth and dental implant and can be considered a treatment alternative for correction of minor defects papilla.
\end{abstract}

Keywords: Implant, Aesthetic area, Papilla reconstruction, Hyaluronic acid.

\section{Introduction}

Today's success in implantology is no longer only associated to the already recognized osseointegration implant but also to the naturalness of the rehabilitation, and in this regard the similarity between the implanted tooth and counter-lateral natural tooth, especially when speaking of single implants in aesthetic regions. The gingival contour is responsible for maintaining the aesthetic traits of the implanted tooth and the presence of the papilla between the teeth and implants makes this crucial. $^{1-4}$

The front teeth papilla is part of the keratinized gingiva and is made up in part of inserted gingiva in the center and free marginal gingiva in the lateral edges having its peak below the point of contact between the teeth formed only by free marginal gingiva. ${ }^{5}$

This interproximal soft tissue was measured in an important study by Gargiulo et al. ${ }^{6}$ in 1960 , where the biologic dimensions of the connective insertion of the junctional epithelium from the depth of the gingival sulcus and the connection of the cement enamel junction to these structures. These biological dimensions until today defined as biologic width, measure $0.97 \mathrm{~mm}$ of epithelial attachment and $1.07 \mathrm{~mm}$ of the connective tissue, which added come to a total average of $2.04 \mathrm{~mm}$.

In 1992, Tarnow et al. ${ }^{7}$ found in their research an association between the contact point distance to the bone crest and the presence of the papilla of which the distance was equal or smaller to $5.0 \mathrm{~mm}$, the papilla was present in $100 \%$ of cases; when the distance was up to $6.0 \mathrm{~mm}$, the papilla was present in $56 \%$ of cases; when the distance was up to $7.0 \mathrm{~mm}$ the papilla was associated from 10 to $27 \%$ of cases. Several other studies on adjacent teeth have confirmed this correlation ${ }^{8-12}$, and have also found a correlation between the distance of the roots and the presence of papilla.

The greatest difference found between teeth and implants in regards to the formation of biologic width is the fact of its formation being above the crest of the tooth and below the crest of implants ${ }^{13-16}$ due to the absence of the periodontal ligament and the more apical bone remodeling by the formation of biological space, ${ }^{15-17}$ being the physiological reabsorption around $1.5 \mathrm{~mm} .{ }^{18,19}$

Likewise the distance between implants, as is the case between two roots, influences the height of the bone crest between them by the lateral bone reabsorption and biologic width formation. ${ }^{19}$ In cases where this distance is smaller than $3.0 \mathrm{~mm}$ the bone crest absorption happens and consequently the distance between the bone crest and the contact point between the teeth or adjacent implants increases, with a resulting decrease of the interproximal papilla. ${ }^{6,8-12,15,16,19,20}$

When implants are placed next to natural teeth there is a better perspective of papilla maintenance, for the height is determined by the biologic width above the crest and not below the crest of the implant because of the fact that the tooth preserves the bone crest. ${ }^{15,20}$ However the maintenance of the bone crest does not necessarily mean a better gingival aesthetics. ${ }^{21}$ Many other factors such as implant placement, surgical technique, implant/abutment model connection and the prosthetic restoration influence gingival aesthetics. ${ }^{22,23}$

The determining fact for the height of the papilla is the bone crest, ${ }^{20,21}$ which is why procedures that cause bone gain must be made prior to the implant installation, such as post-extraction alveolar bone preservation or bone graft. ${ }^{23,24}$ Bone grafts are limited 
within the interproximal region and the lost interdental bone crest will rarely be completely recuperated for the graft techniques in this area are not predictable due to local low blood supply. ${ }^{25}$

Many surgical techniques have been described for the increase in papilla height of which the techniques that use pediculated connective tissue graft obtain better results, although the surgical reconstruction of the implant papilla is difficult and not very predictable ${ }^{2,26}$ due to the deficient blood flow in the interproximal region $^{22,24}$ mainly in the implant region where the irrigation is even less because of the absence of the periodontal ligament. ${ }^{3}$ Another relevant aspect to the surgical techniques taking into consideration possible post-op complications ${ }^{27}$ is that the Literature only shows isolated clinical results despite the absence of longitudinal studies. The use of hyaluronic acid for the increase of papilla may thus be a viable and less invasive alternative.

Because it is biocompatible (non-immunogenic and non-allergic $)^{28}$ having ample use in aesthetic medicine for decades, and for presenting several commercial brands available, hyaluronic acid may be a good alternative as a injectable papilla filler. ${ }^{29,30}$

The objective of this present article is to report a clinical case of injectable hyaluronic acid use associated to the gingival prosthetic conditioning for the increase of the dental papilla height between teeth and implants.

\section{Case Presentation}

Patient S.F., 52 year old female, sought out the Clínica de Especialização de Periodontia da São Leopoldo Mandic (Saint Leopold Mandic Periodonty Specialization Clinic) referred the uncovering of an implant 6 months previously installed. After the initial clinical, $\mathrm{x}$-ray and planning exams the uncovering was scheduled and performed using a blade \#15C where the incision was made above the crest with an elevation of the palatal incision, deepithelization and fold (roll technique $\left.^{31}\right)$. Then the mattress sutures and simple sutures where performed, to increase vestibular tissue volume. A temporary crown was installed over the abutment for a cemented prosthetic. The temporary crown had its cervical region fairly worn down, for tissue migration (Fig. 1).
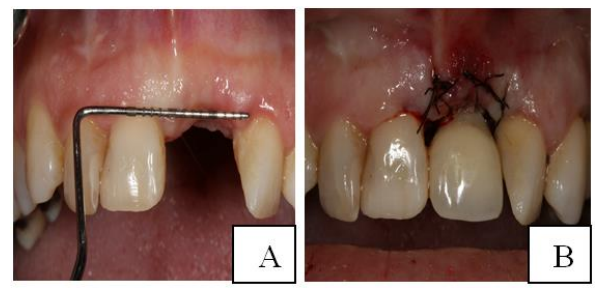

Fig. 1A: Verification of the Relation of the Gingival Margin to the adjacent teeth. (Els. 11,21 e 22)

\section{Fig. 1B - Immediately Post-op with temporary crown replacement over implant and Rolled Suture over incision. (EI)}

In 10 days post-op a satisfactory soft tissue coronal migration was observed, with papilla formation (Fig. 2)

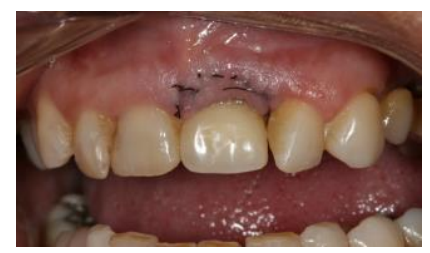

Fig. 2: 10 days post-op. (El. 21)

Sixty days into post-op a margin and papillae apical recession was perceived between the central and lateral left maxilar incisors, forming a "black triangle" (Fig. $3)$.

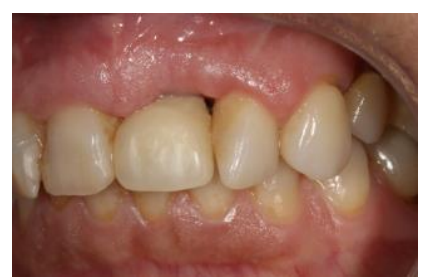

Fig. 3: 60 days into post-op

Note the interdental papilla recession between elements 21 and 22

A reline on the temporary tooth was done for the conditioning of the soft tissue. A non-surgical alternative treatment for papillae increase was proposed between central and lateral left maxilar incisors through the use of hyaluronic acid gel commercially used in aesthetic medicine as a dermal filler.

The patient was informed that this was a new treatment option, and signed a treatment consent form and image rights consent form. The application methodology was based on the work of Becker et al $2010,{ }^{29}$ in which it was reported that the acid must be done $2-3 \mathrm{~mm}$ from the gingival margin. The injection was given 4 times in a 3 -month period with a 0.06 $0.1 \mathrm{ml}$ hyaluronic acid dose for each of the applications (Fig. 4).

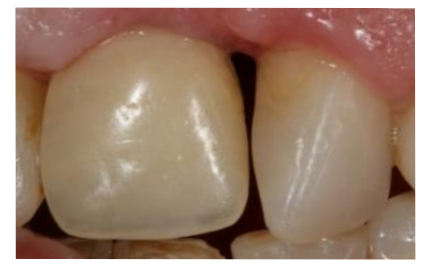

Fig. 4: Result observed after 4 applications of hyaluronic acid. (Els. 21 e 22) 
With the purpose of diminishing the interdental spaces and creating a contact point and performing the rotation correction of left lateral maxilar incisor, by mutual agreement the patient was forwarded for endodontic treatment. The prosthesis preparation and temporary crown were made.

An orthodontic ligature wire was used in the apical portion of the contact point and a periapical x-ray with a positioner was used for measuring the relationship between the contact point to the bone crest (Fig. 5A and B). Then two other hyaluronic acid applications were made within 30 days (Fig. 6).

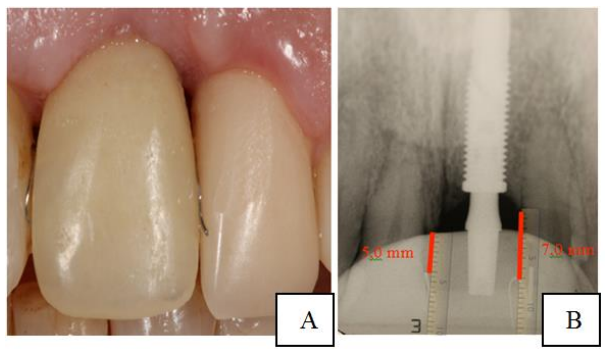

Fig. 5A: Temporary crown of element 22 and point of contact markings with ligature wire

Fig. 5B: Periapical X-ray of element 21 with the measuring from bone crest to contact point (Computerized analysis)

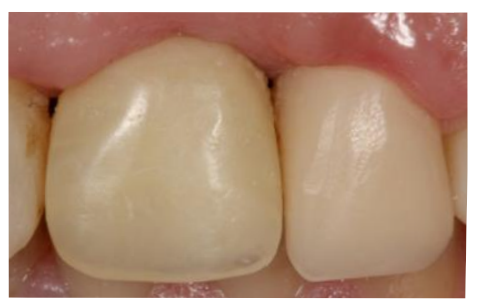

Fig. 6: Papilla after two other applications within a 30 day interval after temporary tooth installation (Els. 21 e 22)

After reaching this objective the option was taken to widen the space between the teeth by wearing down the temporary crown. An intrasulcular incision was performed under local anesthesia to promote the inflammatory process followed by an immediate application of $0.1 \mathrm{ml}$ of hyaluronic acid and thus promoting the increase in papilla height (Fig. 7).

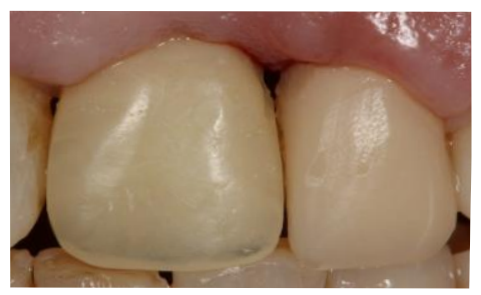

Fig. 7: Widening of the interdental spaces, intrasulcular incision and hyaluronic acid application. (Els 21 e 22)
Seventeen days after this procedure the patient was reevaluated and at that time another acid application was made. An increase in the papilla volume was observed reaching a good filling of the interdental space.

An increase in papilla growth of $1.0 \mathrm{~mm}$ (Fig. 8A and B) was analyzed and measured through computerized comparisons.

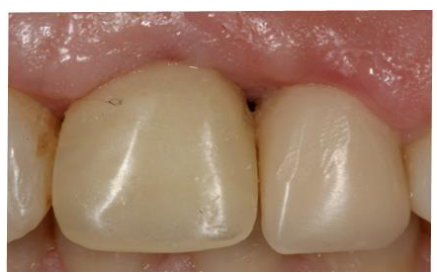

Fig. 8: Reevaluation 17 days after procedure and new hyaluronic acid application. (Els. 21 e 22)

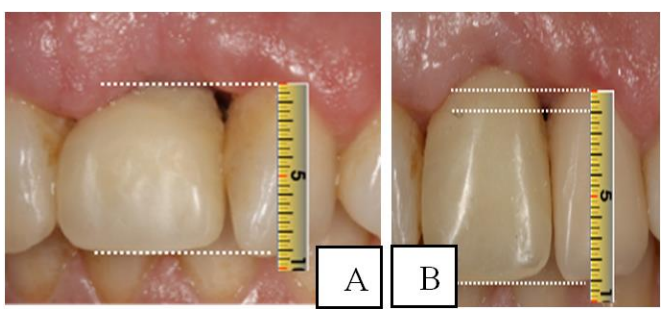

Fig. 9A: Initial reevaluation after 60 days

Fig. 9B: Papilla growth comparison of $1.0 \mathrm{~mm}$ after modifications to point of contact and 8 acid applications

\section{Discussion}

The objective of this research is to evaluate the viability of the use of hyaluronic acid as a papilla filler as an alternative to reconstructive surgical treatment and even as a complement form for surgery provisioning for the limitations in bone tissue or soft tissue growth results.

A treatment alternative for the reconstruction of the papilla is the soft tissue manipulation. ${ }^{3,4}$ Just as the best moment for bone growth is prior or during implant installation, the best moment for soft tissue manipulation is the implant uncovering. Many authors have published uncovering techniques for the reconstruction of papilla through modified flaps. . $^{2,15,22-25}$ With this in mind possibly the best papillae reconstructive surgical techniques are associated to pediculated flaps and connective grafts. ${ }^{23,} 32-34$ In the case of the pediculated flaps there is a greater possibility of connective graft nutrition.

In the present case, during the uncovering of the implant, no previously mentioned technique for the reconstruction of the papillae $e^{2,15,22-25}$ was utilized. The tissue uncovering roll technique ${ }^{31}$ was used to gain thickness on the buccal surface of the gingival margin. In the same manner, no type of connective tissue graft 
was planned after the temporary crown was installed. ${ }^{23,32-34}$

Furthermore after an initial positive result a recession and loss of papillae was observed due to the large distance from the bone crest to the tip of the papillae $(7.0 \mathrm{~mm})$ and consequently lack of sufficient soft tissue, besides the absence of an interproximal contact point.

Altering the proximal-cervical shape of the tooth or implants crowns changes the emergence profile. If it is too narrow it doesn't compress the soft tissue, and consequently doesn't form the papilla and on the other hand if it is too wide it compresses the papilla vertically which in turn hinders hygiene and collapses it. ${ }^{3}$ This crown shape modification also makes the point of contact more apical ${ }^{2,4}$ improving the visual aspect, thus hiding the black triangle, though still being aesthetically unsatisfactory due to the change in its shape. ${ }^{1}$ However it is still unclear if the setting of the apical contact point reestablishes the papilla ${ }^{12}$ and with or without the reestablishment of the contact point, if the new papilla will be formed according to the biologic dimensions of the soft tissue. ${ }^{35}$

Based on several variables it is possible to determine that what really affects the preservation of the papillae is the height of the bone crest and the thickness of the soft tissue.

Previous studies show that the implant installed and its connection with the abutment under the crest cause bone reabsorption by the formation of new biological space. ${ }^{1,2,18-21}$ In this present case report the implant used is characterized by a prosthetic connection like Platform Switching which comparing to other connection systems promotes a smaller bone absorption and possible supra-crestal biologic width formation. ${ }^{20,21}$ This is the reason for opting for gaining soft tissue through the hyaluronic acid gel injection.

The use of injectable fillers for the increase of interdental papilla may be recommended. ${ }^{29,30,36}$ A study performed by McGuire and Scheyer, ${ }^{37}$ used autologous fiberblast grafts (tuber biopsy) expanded in laboratory, performing intrasulcus incisions in the first application to induce the inflammatory process, followed by repeated applications in a 7 to 14 day interval for 4 months. This experiment reached good results, though inconclusive due to the difficulties of being precise on the methodology of the comparative measurements of the results. Another study done by Becker et al ${ }^{29}$, used hyaluronic acid commercially available to correct deficient papillae in the anterior region of the maxilla, along with photographic records of the evolution through the analysis of the black triangle in the pixels of the pictures, then converted into millimeters through a mathematic formula. Up to 3 applications were made in 3-week intervals between them in 14 sites: obtaining $100 \%$ filling in 2 sites; $94-97 \%$ growth in 7 sites; 76$88 \%$ growth in 3 sites; and 1 site that had a $57 \%$ growth. These results contrast to 2 recent studies from Lee et al. ${ }^{38,39}$ using photographic methodology of more effective measurements, using up to 5 applications of commercial hyaluronic acid gel in 3 -week intervals in 43 sites where $67 \%$ of the black spaces of the sites were $100 \%$ filled. The remaining sites had an average filling of $87 \%$. Differences were explained by the direct relationship between the bone crest distance to the point of contact and the inability of complete papillae restoration.

Awartani and Tatakis ${ }^{40}$, have repeated the methodology used by Becker et al, ${ }^{29}$ reaching similar clinical results besides interesting result perspective observed by the patients through a questionnaire form, where $2 / 3$ of the patients appreciated the results and would repeat the procedure.

The hyaluronic acid is a polysaccharide present on the connective tissue of vertebrate beings in regions such as the umbilical cord, synovial fluid, skin, the vitreous body, lungs, kidneys, brain and muscles, liver and blood plasma. ${ }^{41-43}$ It is synthesized by fiberblasts and keratinocytes in the gingiva and periodontal ligaments, by the cementoblasts in cement and the osteoblasts in the alveolar bone. ${ }^{28,41}$

The hyaluronic acid performs important cellular functions, actively participating in tissue hydrodynamics, proliferation processes, cellular migration and differentiation and angiogenesis. ${ }^{30,42,43}$ When modified, it can promote the growth of fiberblasts. ${ }^{30}$ These properties suggest that it produces connective tissue growth and consequently papillae growth.

Another possible hypothesis is that the increase in connective tissue through the use of hyaluronic acid is due to liquid retention, through its hygroscopic capacity, since in vitro studies show that $1 \mathrm{~g}$ of the product can bond to $6 \mathrm{~L}$ of water. ${ }^{28,30,36}$

In the present case after 4 applications in the 3 month interval before the creation of the contact point, no changes were observed in the dimensions of the papilla. After the creation of the point of contact, even in the case of being $7.0 \mathrm{~mm}$ from the bone crest, it was noticeable that after 2 applications and in a 35-day interval, there was an increase of $0.5 \mathrm{~mm}$ of the interdental papilla.

After the opening of the space in gingival embrasure and 4 more applications in a 28-day interval, a growth of $1.0 \mathrm{~mm}$ was observed in the papilla height, demonstrating that the hyaluronic acid can be a good treatment option for the increase of small papilla deficiencies.

\section{Conclusion}

It is observable in this case that the use of injectable hyaluronic acid associated to gingival prosthetic conditioning will lead to the growth of the interdental papilla between tooth and dental implant, 
therefore it is possible to consider this as an alternative for surgical treatment of soft tissue manipulation for the reconstruction of the papillae. It would be necessary to follow up on the results for a greater period of time to properly evaluate the long term results and possible relapse.

\section{References}

1. Park JH, Tai K, Morris J and Modrin D. Clinical considerations of open gingival embrasures, Pathogenesis and Treatment of Periodontitis. Intechopen 2012;113-127 em www.intechopen.com (acesso out 2015).

2. 2- Grossberg DE. Interimplant Papilla Reconstruction: Assessmet of soft tissue changes and results of 12 consecutive cases. J Periodontol 2001;72(10): 958-962 21 - Pradeep AR and Karthikeyan. Peri-implant papilla reconstruction: realities and limitations. J Periodontol 2008;77(3):534-544.

3. Pradeep AR and Karthikeyan. Peri-implant papilla reconstruction: realities and limitations. J Periodontol 2008;77(3):534-544.

4. Oliveira JD, Storrer CM, Sousa AM, Lopes TR, Vieira JS, Deliberador TM. Papillary regeneration: anatomical aspects and treatment approaches. RSBO. 2012;9(4):448456.

5. Carranza FA, Newman MG, Takei HH, Klokkevold PR. Carranza, Periodontia clínica. $11 \underline{\alpha}$ Ed. Saunders Elsevier. 2011.

6. Gargiulo AW, Wentz FM, Orban B. Dimensions of the dentogingival junction in humans. J Periodontol 1961;32:261-7.

7. Tarnow DP, Magner AW, Fletcher P. The effect of the distance from the contact point to the crest of bone on the presence or absence of the intreproximal dental papilla. J Periodontol. 1992;63(12):995-996.

8. Wu YJ, Tu YK, Huang SM, Chan CP. The influence of the distance from the contact point to the crest of bone on the presence of the interproximal dental papilla. Chang Gung Med J. 2003;26(11):822-828.

9. Cho HS, Jang HS, Kim DK, et al. The effects of inter proximal distance btween roots on the existence of interdental papillae according to the distance from the contact point to the alveolar crest. J Periodontol 2006; 77:1651-1657.

10. Martegani P, Silvestri M, Mascarello F, Scipioni T, Ghezzi C, Rota C and Cattaneo V. Morphometric study of the interproximal unit in the esthetic region to correlate anatomic variables affecting the aspect of tissue embrasure space. J Periodontol 2007;78(12);2260-2265.

11. Tamsailom S, Torsricharoen T, Thanaratikul B. The relationship between vertical and horizontal dimensions of inter proximal embrasure and the presence of interdental papilla in maxillary anterior teeth. Thai Board of Periodontology 2010;2553;33:163-72.

12. Chen M, Liao Y, Chan C, Ku Y, Pan W and Kang Y. Factors influencing the presence of inter proximal dental papillae between maxillary anterior teeth. J Periodontol 2010;81:318-324.

13. Cochran DL, Hermann J.S., Schenk R.K., HiggenBotton F.L., Buser D. Biologic width around titanium implants. A histometric analysis of the implant-gingival junction around unloaded and loaded non-submerged implants in the canine mandible. J Periodontol 1997;68(2);186-197.

14. Adell R, Eriksson B, Lekholm U, Branemark PI, Jemt T. Long-Term follow-up study of osseointegrated implants in the treatment of totally edentulous jaws. Int J Oral Maxillofac Implants. 1990;5(4);365-371.

15. Choquet V, Hermans M, Adriaenssens P, Daelemans P, Tarnow D and Malevez C. Clinical and radiographic evaluation of the papilla level adjacent to single-tooth dental implants. A retrospective study in the maxillary anterior region. J Periodontol 2001;72(10):1364-1371.

16. Tarnow DP, Elian N, Fletcher P. Vertical distance from de crest of bone to the height of the inter proximal papilla between adjacent implants. J Periodontol 2003;74(12):1785-1788.

17. Tarnow D, Stahl SS, Magner A, Zamzack J. Human gingival attachment responses to subgingival crown placement. Marginal remodelling. J Clin Periodontol. 1986:13(6);563-9.

18. Albrektsson T, Isidor F, Consensus report of session IV. In: Lang NP, Karring T, eds. Proceedings of the 1 st European Workshop of Periodontology. London: Quintessence Publishing:1994:365-369.

19. Tarnow DP, Cho SC, Wallace SS. The effect of interimplant distance on the height of inter-implant bone crest. J Periodontol. 2000;71(4):546-549.

20. Kwon HJ, Lee DW, Park KH, Kim CK, Moon IS. Influence of the tooth-and implant-side marginal bone level on the inter proximal papilla dimension in a single implant with microthread, conical seal, and platformswitched design. J Periodontol 2009; 80(9):1541-1547.

21. Atieh MA, Ibrahim HM and Atieh AH. Platform switching for marginal bone preservation around dental implants: A systematic review and meta-analysis. J Periodontol 2010;81(10):1350-1366.

22. Blatz MB, Hurzeler MB, Strub JR. Reconstruction of the lost papilla - presentation of surgical and nonsurgical approches. Int J Periodontics Restorative Dent. 1999;(19):395-406.

23. Azzi R, Etienne D, Carranza F. Surgical reconstruction of the interdental papilla. Int J Periodontics Restorative Dent. 1998;(18):467-73.

24. Nemcovski CE, Moses O and Artzi Z. Interproximal papillae reconstruction in maxillary implants. $\mathrm{J}$ Periodontol. 2000;(71):308-314.

25. Palacci $P$ and Nowzari H. Soft Tissue enhancement around dental implants. Periodontology 2000. 2008;47:113-132.

26. Jemt $\mathrm{T}$. Regeneration of gingival papillae after single implant treatment. Int J Periodontics Restorative Dent 1997; 17:326-333.

27. Griffin TJ, Cheung WS, Zavras AI and Damoulis PD. Postoperative Complications Following Gingival Augmentation Procedures. J Periodontol. 2006;(77):20702079.

28. Dahiya P e Kamal P. Hyaluronic acid: A Boon in Periodontal Therapy. North American Journal of Medical Sciences. 2013;5(5):309-315.

29. Becker W, Gabitov I, Stepanov M, Kois J, Smidt A, Becker BE. Minimally invasive tretament for papillae deficiencies in the esthetic zone: A pilot study. Clinical Implant Dentistry and Related Research. 2010;12(1):1-8.

30. Ballini A, Cantore S, Capodiferro S, Grassi FR. Esterified hyaluronic acid and autologus bone in the surgical correction of the intra-bone defects. International Journal of Medical Sciences. 2009;21(4):575-578.

31. Abrams L. Augmentation of the deformed residual edentulous ridge for fixed prosthesis. Compound Contin Educ Dent. 1980;1:3,205-213.

32. Han TJ, Takei HH. Progress in gingival papilla reconstruction. Periodontology 2000. 1996;(11):65-68. 
33. Nordland WP, Sandhu HS. Microsurgical technique for augmentation of the interdental papilla: Three case reports. Quintessence Publishing. 2008;(28):543-549.

34. Carranza N, Zogbi C. Reconstruction of the interdental papilla with an underlying subepithelial connective tissue graft: Technical considerations and case reports. Quintessence Publishing CO. 2011;31(5):45-50.

35. Papalexiou V, Novaes Jr. AB, Macedo GO, Luczyszyn SM, Muglia VA. Preprosthetic periodontal surgery in the proximal area with modification of the COL area: Results following the reestablishment of the contact point. J Peroidontol. 2006;77:1856-1862.

36. Bansal J, Kedige SD, Anand S. Hyaluronic acid: A promising mediator for periodontal regeneration. Indian Journal of Dental Research. 2010;21(4):575-578.

37. McGuire MK, Scheyer ET. A Randomized, double-blind, placebo-controlled study to determine the safety and efficacy of cultured and expanded autologous fibroblast injections for the treatment of interdental papillary insufficiency associated with the papilla priming procedure. J Periodontol. 2007;78:4-17.

38. Lee WP, Kim HJ, Yu SJ, Kim BO. Six month clinical evaluation of interdental papilla reconstruction with injectable hyaluronic acid using an image analysis system. J of Esthetic an Rest Dent. 2016;00:1-10

39. Lee WP, Seo YS, Kim HJ, Yu SJ, Kim BO. The association between radiographic embrasure morphology and interdental papilla reconstruction using injectable hyaluronic acid gel. J Periodontal Implant Sci. 2016;46(4):277-287

40. Awartani FA, Tatakis DN. Interdental papilla loss: treatment by hyaluronic acid gel injection. Cila Oral Invest. 2016;20(7):1775-80

41. Demarosi F et al. Hyaluronic acid: biological effects and clinical applications. 2007 Disponível em <http://www.yourdent.co.il/UserFiles/Image/pdf/profCarr assi.pdff $>$. Acesso em Jul 2014.

42. Liu L, Liu Y, Li J, Du G, Chen J. Microbial production of hyaluronic acid: current state, challenges, and perspectives. Microbial Cell Factories. 2011;(10):1-9.

43. Noble PW, Liang J, Jiang D. Hyaluronian as an immune regulator in human diseases. Physiological Reviews. 2011;91(1):221-264. 